\title{
Two kinds of short-term storage '
}

HERMAN BUSCHKE 2

DIVISION OF NEUROLOGY, STANFORD UNIVERSITY

The hypothesis that same-order and natural serial-order recall of numbers use a common short-term storage was tested by requiring either same-order or serial-order recall on two successive presentations of the same sequence. The results show the use of two different short-term storages, retaining information which refers to appropriate responses in longterm storage.

Retention in and retrieval from short-term memory may be organized in terms of characteristics of the presentation or characteristics of the events. For sequentially presented numbers this is illustrated by same-order recall (e.g., in order of presentation) and by natural serial-order recall (e.g., from lowest to highest number), respectively. If $8,3,1,6$ are presented, same-order recall is $8,3,1,6$ and serialorder recall is $1,3,6,8$.

It has been shown that same-order recall is orderdependent but serial-order recall is not, that error curves for same-order and serial-order recall differ substantially and systematically for both serial position and number (Buschke, 1966), and that sameorder recall may be differentially impaired by braindamage when serial-order recall remains relatively intact (Buschke, 1965). Those findings indicate either two kinds of recall from a single short-term storage (STS), or two kinds of storage, each with its own appropriate retrieval process. Kind of STS may be reformulated as kind of information retained in STS. This paper reports an experiment showing that different kinds of information are retained in STS for same-order and for serial-order recall.

\section{Method}

Random sequences of eight numbers from 1 through 16 were presented aurally at a rate of about $1 / \mathrm{sec}$. Each sequence was presented twice on two successive trials for recall immediately after each presentation. Four conditions are determined by type of recall on the two trials: recall in same order as presented on both trials (Same-Same), recall in serial order on both trials (Serial-Serial), sameorder recall on the first trial and serial-order recall on the second (Same-Serial), and serial-order recall on the first trial and same-order recall on the second (Serial-Same). Each condition contained 16 different sequences of eight numbers, the list of sequences for each condition being different from but isomorphic with the other lists. All conditions were presented to all Ss in blocks, the order of which was counterbalanced across Ss.
The 24 Ss were college students paid for participation. Ss were instructed to report verbally numbers just presented either by same-order recall or by serial-order recall (from lowest to highest number), as appropriate, and also any others remembered even if out of order. Eight different responses were required on each trial and were scored as correct if they occurred in that trial, regardless of order of recall.

Results

Table 1 shows mean recall (irrespective of order of recall) for all first and second trials (maximum possible is 128). Significant overall differences are shown by Friedman rank analysis of variance $\left(\mathrm{X}_{\mathrm{r}}^{2}=\right.$ 58, df $=7, p<.001$ ); data are evaluated by two-tailed sign tests (Siegel, 1956). The major findings are that: Serial-order recall did not increase following same-order recall (Same-Serial < Serial-Serial, $p=.01$; Same-Serial $=$ Serial-Serial, $p=.832$ ), although it did increase following serial-order recall (Serial-Serial) Serial-Serial, $p<.004$ ). Same-order recall increased following serial-order recall as well as following same-order recall (Serial-Same $=$ Same-Same, $p=.664$; Same-Same $>$ Same-Same, $\mathrm{p}<.002$ ), but serial-order recall preceding same-order recall was decreased (Serial-Same $<$ Serial-Serial, $p=.01$ ). There was no significant difference between serial-order and sameorder recall in homogeneous conditions when the same kind of recall was used on both trials.

The data show that while learning occurs for serialorder recall as well as for same-order recall, serialorder recall is impaired when preceded or followed by same-order recall. When learning occurs for same-order recall following serial-order recall, there is impairment of the preceding serial-order recall. Discussion

Serial-order recall cannot retrieve from a STS appropriate for same-order recall but can retrieve from a STS appropriate for serial-order recall. This indicates not only that serial-order and same-order recall involve different short-term storages (in the sense that different kinds of information are retained

Table 1. Mean number of items retrieved by same-order and natural serial-order recall.

\begin{tabular}{lccccc} 
& $\begin{array}{c}\text { Same } \\
\text { Serial }\end{array}$ & $\begin{array}{c}\text { Serial } \\
\text { Serial }\end{array}$ & $\begin{array}{c}\text { Serial } \\
\text { Same }\end{array}$ & $\begin{array}{c}\text { Same } \\
\text { Same }\end{array}$ \\
\hline First trial & 111.29 & $108.29>105.75$ & 108.38 \\
Second trial & 109.08 & $<113.54$ & $114.21=114.67$ \\
\hline
\end{tabular}


in STS), but also that the information retained for same-order recall is not simply information about events and information about their order. Information about the sheer occurrence of events (regardless of their order) retained for same-order recall itself appears to be order-dependent. Moreover, since the kind of STS used seems to depend on the kind of retrieval anticipated, analysis of short-term storage may require the use of retrieval-free methods (Buschke \& Lim, 1967).

The increase in same-order recall following serialorder recall indicates storage of information about presented events, rather than about Ss' output in learning response sequences. It is unlikely that this finding means that same-order recall may be used to retrieve from STS suitable for serial-order recall, since serial-order recall was decreased preceding same-order recall. Instead, the impairment of serialorder recall both preceding and following same-order recall indicates that Ss may adopt different sets or strategies to use STS appropriate for either sameorder or serial-order recall, and preferentially use STS for same-order recall when both kinds of recall will be required. This also indicates that same-order and serial-order recall involve different kinds of STS.

Two kinds of STS (of information about the same events) indicates that information in STS is not directly about presented events per se, or attributes by which events are identified (perceived), or (verbal) labels for sets of attributes. Rather, what is retained in STS seems to be reference information providing access to contents of long-term storage (LTS) necessary for readout from STS and response about presented events. If information in STS were about events, their attributes, or their labels, then it should be available for both same-order and serial-order recall of sheer occurrence. But this was not found here, so it appears that what is stored in STS is information relating input to readout and response (i.e., reference information about which events in LTS occurred), and that the form of such reference information is different for same-order and serial-order recall. This interpretation seems reasonable, since readout from STS presumably requires reference to appropriate response information in LTS.

\section{References}

Buschke, H. Impairment of short-term memory. Neurology, 1965, 15, 913-918.

Buschke, H. Types of immediate menory. J. verbal Learn. verbal Behav., 1966, 5, 275-278.

Buschke, H., \& Lim, H. Temporal and interactional effects in short-term storage. Percept. \& Psychophys., 1967, 2, 107-114. Siegel, A. Non-parametric statistics. New York: McGraw-Hill, 1956.

\section{Notes}

1. Supported by U.S.P.H. Research Grant Mit-08556 to Herman Buschke from the National Institute of Mental Health. The author wishes to thank Richard Lenon for assistance in testing subjects. 2. Supported by U.S.P.H. Research Career Development Award K3-MH-23,796 to Herman Buschke from the National Institute of Mental Health. 